\title{
Effects of Interpersonal Problems at Workplace on Job Involvement
}

\author{
Mozumdar Arifa Ahmed
}

Lecturer, Faculty of Business Administration, Eastern University, Bangladesh

\begin{abstract}
Job involvement plays an important role to create positive job attitude which indicates strong psychological bonding of an employee to his or her job. On the other hand interpersonal problems at workplace make job conflict, increase job stress which is threatening to create positive job attitudes. The objective of this study was to investigate the relationship between interpersonal problems and job involvement, to explore how different types of interpersonal problems effect on job involvement and to examine the problem areas of interpersonal relationship in workplace that can create negative impact on job involvement. The measuring instruments used in this study were: Inventory of Interpersonal Problems (IIP-64) (Alden, Wiggins, Pincus \& Horowitz, 2000) for measuring different types of interpersonal problems. And Work Involvement Scale (Kanungo, 1982) for measuring job involvement. According to the objective of the present study the obtain data were analyzed using Pearson product moment correlation and simple regression. The survey results revealed that interpersonal problem is negatively correlated to job involvement. The study also found that the people who are mostly face problems in cold / distant, overly accommodating and intrusive/needy domains in case of interpersonal relationship; they are more at risk to be less involved with job.
\end{abstract}

Key words: Interpersonal relationship; interpersonal conflict; interpersonal problems; job stress, job attitudes.

\section{JEL Classification Code: M12}

\section{INTRODUCTION}

The work environment is an important aspect of employee's work life that can affect on job attitudes in a positive and negative way. And an important component of the work environment is interpersonal relationships which are considered as an essential part of the psychosocial working conditions. Stress free, peaceful and trustworthy working conditions help people to perform the tasks well and to concentrate on the job more effectively.

1.1 Interpersonal relationship:

Interpersonal relationships defined as the interaction between co-workers or managers in everyday working conditions. It serves a critical role in the development and maintenance of trust and positive feelings to the employees in an organization. 


\subsection{Interpersonal Problems:}

Although humans are fundamentally social creatures, interpersonal relationships are not always healthy. While interpersonal relationships may influence us in positive ways, they may also have important negative effects (Berscheid \& Reis, 1998). Examples of unhealthy relationships include interpersonal problems. Interpersonal problems are recurrent difficulties in relating to others. (Horowitz, Rosenberg, \& Bartholomew, 1993) "Interpersonal circle" (Kiesler, 1983) can be subdivided into eight octants. The present study tries to give emphasis on those eight sectors which are closely related with personality traits and describe the interpersonal problems from an individual view point. The sectors are-

\subsubsection{Domineering/ Controlling}

Domineering/ Controlling indicates difficulties in relinquishing control over others. People with described themselves as too controlling or manipulative. They might characterize their efforts to influence other people as hostile, but the emphasis here is more on control than hostility. Sometimes a loss of control is threatening to the person because it produces a feeling that he or she has lost dignity, worth, or self- respect. In extreme cases, the person's very identity is threatened- the person's sense of self gets rattled whenever another person sense seems to be giving him or her orders, guidance or instruction. Indeed, some people find it so unpleasant to relax control that they can not even listen to another person's point of view without challenging it. Unable to consider another person's perspective, the individual may argue excessively with others.

\subsubsection{Vindictive / Self-centered}

Vindictive / Self-centered describes problems of hostile dominance. The person readily experiences and expresses anger and irritability, is preoccupied with getting revenge, fights too much with other people. Person with this type of problem reflects distrust of and suspiciousness toward other people; the person suspects, for example, that other people are being exploitive or deceptive. The person hold grudges and finds it difficulty to forgive insults or slights. As a result the person reports feeling little support or concern for other people and not caring much about their needs, happiness, success or welfare.

\subsubsection{Cold / Distant}

Cold / Distant refers to low degrees of affection for and little connection with others. People with this problem not feel close to or loving toward others, and they find it hard to make and maintain long term commitments to other people. Such a person may describe himself or herself as a lone wolf, even enjoying the apparent freedom from social obligations, social conventions and other demands. However the person has come to realize that, relative to other people he or she is unusually lacking in sympathy, nurturance, generosity, forgiveness and warmth.

\subsubsection{Socially Inhibited}

Socially Inhibited indicates feelings of anxiety, timidity, or embarrassment in the presence of other people. The person finds it hard to initiate social interactions, express feelings to other people, join groups, or socialize. People who are socially avoidant are described as introverted, aloof, distant, and unsociable. In order to avoid humiliation, criticism, disapproval, or rejection, they have come to limit their social life and avoid activities that seem to entail personal social risks; for this reason they often refuse social invitations. Such 
people do not desire or enjoy close relationships; they almost always choose solitary activities and lack close friends or confidants.

\subsubsection{Nonassertive}

Nonassertive indicates a severe lack of self confidence and self esteem. People with it describes as self doubting and unassertive. They have difficulty taking the initiative or being the center of attention. They especially avoid situations that involve social challenge or require the exercise of power or influence over other people (e.g., being another person's boss, expressing opinions authoritatively). Similarly, they have difficulty being firm with other people and sticking to their guns in the face opposition. Other people's disapproval or negative evaluation threatens their already shaky self esteem so they avoid making their wishes and needs known.

\subsubsection{Overly Accommodating}

Overly Accommodating indicates an excess of friendly submissiveness. In an effort to please other people and win their approval, they try to be inoffensive. They are reluctant to say no to other people and allow themselves to be easily persuaded. They may be contrasted with people whose problems fall in the vindictive or self centered; instead, they are loathe expressing or even to feel anger, lest they incur another person's hostility or retaliation. They assume that assertive acts offend and they avoid being assertive in order to maintain friendly relationships. They characterize themselves as obliging, accommodating, deferential, and gentle; they freely acknowledge their own errors and avoid being argumentative, egotistical or devious. Among their problems, they report being too exploitable, too easily taken advantage of by others and too gullible.

\subsubsection{Self-Sacrificing}

Self-Sacrificing indicates a tendency to affiliate excessively. The people in this domain regard themselves as warm, nurturant, generous and use terms like kind, sympathetic, forgiving to describe them. They easily connect with other people emotionally and readily provide help and care for people in need. However, these socially desirable characteristics have become problematic; describe themselves as too eager to serve and too ready to givetoo generous, too caring, too trusting and too permissive. They complain that they find it difficult to set limits, to maintain boundaries on other people. He or she empathizes too readily with another person's misery and experiences the other person's needs as extremely pressing. They put other people's need before their own. This protective attitude towards others also makes it difficult to permit themselves to feel angry toward someone they like. In this way, they protect other people from their own hostility, anger or aggression.

\subsubsection{Intrusive/Needy}

Intrusive/Needy- describes problems with friendly dominance. People with it describe themselves as friendly, outgoing, and sociable. The person has a powerful need to feel engaged with other people and imposes his or her presence onto their attention. The person finds it difficulty to spend time alone. The person may disclose personal things in appropriately, involve himself or herself in another person's business in ways that others find offensive, and take in appropriate responsibility for solving other people's problems. In a word, the person's poor boundaries create interpersonal difficulty. People with it 
report that they open up too much, tell personal things too much and have a hard time keeping things private from other people.

\subsection{Job Involvement:}

Involvement with different aspects of our lives, for instance work, family, religion or sport is characteristic of mankind. Individuals particularly get involved in certain activities when it is seen as having a potential of satisfying certain salient psychological needs (Kanungo, 1979, 1982b). Job involvement one of those fundamentally important factors in most people's work lives, implying being positively absorbed in fundamental aspects of the job (Kanungo, 1982b). It has positive organisational implications, influencing the degree to which the person supports organisational goals, and thus advancing productivity and efficiency (Brown, 1996). A positive state of intense psychological identification with one's job also leads to positive personal results of motivation, goal directed behaviour, personal growth and work satisfaction (Hackman \& Lawler, 1971; Kahn, 1990; Lawler \& Hall, 1970; Schultz \& Schultz, 1994).

Job involvement can be elaborated that it is engagement regarding the internalization of values about the righteousness of work or the significance of work in the value of the individual (Lodahl \& Kejner, 1965). It is a belief about one's current job and is a function of how much the job can satisfy one's wishes. Highly job involved individuals make the job a central part of their personal character. Besides, people with high job involvement focus most of their attention on their job (Hackett et al., 2001).

Job involvement is grouped into four diverse categories. These categories: 1) work as a central life interest, 2) active participation in the job, 3) performance as central to selfesteem, and 4) performance compatible with self-concept. In work as a central life interest, job involvement is thought of as the degree to which a person regards the work situation as important and as central to his/her identity because of the opportunity to satisfy main needs. In active participation in the job, high job involvement hints the opportunity to make job decisions, to make an important contribution to company goals, and selfdetermination. Active participation in the job is thought to ease the achievement of such needs as prestige, self-respect, autonomy, and self-regard. In performance as central to self-esteem, job involvement implies that performance on the job is central to his/her sense of worth. (Blau \& Boal, 1987).

Job involvement is a function of individual difference and the work situation. Thus demographic and work experience variables are expected to relate to job involvement. Positive relationships are expected with age, tenure, years in occupation, education, having children, and gender. Job involvement is negatively associated with intentions to quit and positively related to job satisfaction and organizational climate perceptions (McElroy et al., 1995).

Individuals with high levels of job involvement should be the most motivated to go to work and to go on time. Individuals with low levels of job involvement should be the least motivated. Both highly motivated and non-motivated employees may miss work or come late for excusable reasons (e.g., illness, religious holiday, vacation time, and transportation problems). However, highly motivated employees cannot be thought as non-motivated employees to miss work or come late for inexcusable reasons. Individuals with higher levels 
of job involvement is likely to exhibit less unexcused lateness and unexcused absence than individuals with lower levels of job involvement (Blau, 1986; Blau \& Boal, 1987).

Developing positive attitude job involvement helps in overcoming stress, increases self esteem, confidence, and makes a person more productive or dynamic. Positive attitudes towards job also help to create a positive work environment, to encourage team building, to achieve goals and to increase productivity level.

Job involvement has significant impact on organizational and individual performance. If individual is involved in his job, he will probably be satisfied with job and committed to the organization (Knoop \& Robert, 1995). Perspective of financial need (Gould \& Werbel, 1983) regarding job involvement and organization commitment been studied by different researcher. Research on job involvement and organizational commitment on nurses showed that both have important predictors of unconstitutional tardiness and absence (Blau, 1986).

\subsection{Literature Review}

A deterioration of the organizational environment is accompanied by deterioration in organizational communication (Gilberg, 1993). A social cognitive approach to understanding interpersonal problems assumes that people who react differently to social situations think differently about those situations. It influence on interpersonal demands and - expectations about how others will react to the self and how the self will respond to those reactions. These individual differences in interpersonal expectations may explain some of the individual differences in interpersonal problems (Pierce\&Lydon, 1998).

Interpersonal stress at work is concerned with the demands that are placed on us in developing working relationships with other people in our organizations (Knotts, 1996). Employees who suffer a lot of interpersonal problems may react more actively by creating interpersonal and intraorganizational conflicts involving escalating levels of communication problems. Workers may also experience effects in their psychological and physical health. Psychological consequences of interpersonal conflicts may include anxiety, boredom, low self-esteem, forgetfulness, depression, anger, apathy, or worry. These results are just a few of many stress outcomes that may result from the effects of interpersonal difficulties. Workers may also exhibit deviations in their behavior. Examples of departures from normal behavior may be overeating/loss of appetite, smoking, alcohol abuse, sleeping disorders, emotional outbursts, or violence and aggression (Randolfi, 1996). From the organizational aspect, it has many consequences. Reductions in effectiveness, productivity, and communication are results that are not as easy to identify; however, such outcomes can be among the most debilitating for both the organization and for the individual. Other results may include accidents in the workplace, job turnover, low morale, poor work relations, poor organizational climate, and absenteeism (Randolfi, 1996). "Absenteeism, for example, results in $4 \%$ of the work hours which are lost, and translates into millions of dollars annually" (Knotts, 1996).

Interpersonal difficulties related to interdepartmental activities within an organization included issues such as poor cooperation, organizational politics, and similar activities. Certain behaviors associated with job burnout have been observed in a wide variety of occupations. These behaviors include a tendency on the part of an individual to blame others in an organization for one's own problems, increased absenteeism, increased 
involvement in interpersonal conflicts and confrontation, and increasing isolation from others in the organization (Maslack, 1997). Individuals suffering from job burnout frequently attempt to remove themselves from the situations they perceive to be the source of their problems without actually terminating their jobs. Their strategies in such attempts involve a breakdown in communication, and are often damaging to both their organizations and to their own careers. That's why this research will explore the effect of interpersonal problems on job involvement.

\subsection{Hypothesis}

On the basis of literature review following hypothesis was developed:

Hypothesis 1. Interpersonal problem is negatively related to Job involvement.

\subsection{Research Questions}

The research problem addressed through these research questions,

$>$ Is job involvement related with the interpersonal problems?

$>$ What are the aspects of interpersonal problems that can affect job involvement?

$>$ Which type of interpersonal problems is more vulnerable for job involvement?

\subsection{Objectives:}

This research has the following objectives:

$>$ To investigate the relationship between interpersonal problems and job involvement.

$>$ To explore how different types of interpersonal problems effect on job involvement.

> To examine the problem areas of interpersonal relationship in workplace that can create negative impact on job involvement.

\section{Methodology}

\subsection{Participants}

The population of this research was 250 bankers working in different private banks in Bangladesh. According to annual report of Bangladesh Bank 2010, there are 33 private banks in Bangladesh. The research was conducted within Dhaka. The research sample was selected based on the simple random sampling technique from the list of bankers. For identifying the sample size, confidence level is $95 \%$ and confidence interval is 10 .

\subsection{Data Collection}

To examine the research questions both primary and secondary data were obtained from different sources.

\subsubsection{Primary Data}

The primary data was collected by using the measuring scales.

Measures used

To measure the independent and dependent variables (interpersonal problems and job involvement) the following measuring scales were used.

$>$ Inventory of Interpersonal Problems (IIP-64) (Alden, Wiggins, Pincus \& Horowitz, 2000) for measuring different types of interpersonal problems.

$>\quad$ Work Involvement Scale (Kanungo, 1982) for measuring job involvement.

In addition a Demographic Information Blank was also used made by present researcher.

2.2.1.1 Inventory of Interpersonal Problem (IIP-64): 
Inventory of Interpersonal Problems (IIP-64) (Alden, Wiggins, Pincus \& Horowitz, 2000) was used to measure different types of interpersonal problems. The Inventory of Interpersonal Problems (IIP-64) is a self-report instrument that identifies a person's most salient interpersonal difficulties. The IIP-64 contains 64 statements describing common interpersonal problems drawn from an original pool of 127 items. This instrument may be administered to individuals or groups. The test and norms are approved for adults (18 years and older). The items of IIP-64 are divided into two sections: One section begins "The following are things you find hard to do with other people"; the other section begins "The following are things that you do too much". The IIP-64 contains the following eight subscales- Domineering/Controlling, Vindictive/Self-centered, Cold/Distant, Socially Inhibited, Nonassertive, Overly Accommodating, Self-Sacrificing, Intrusive/Needy. The original inventory consists of high level of test-retest reliability ( $\mathrm{r}=0.56-0.76$; for 8 subscales) and inter subscales correlation of 0.76 to 0.86 . The original inventory contains high external validity. The correlation between IIP-64 and Beck Depression Inventory II was found 0.33 to 0.48 for 8 subscales. Also the correlation between IIP-64 and Beck Anxiety Inventory was found 0.31 to 0.44 for 8 subscales.

\subsubsection{Work Involvement Scale}

Job involvement was measured with the ten-item/Job Involvement Scale developed by Kanungo (1982). This scale measures the degree of psychological importance of one's job using a five-point Likert scale $(1=$ strongly disagree to $5=$ strongly agree). Sample items included "I consider my job to be very central to my existence" and "I am very much personally involved in my job." The internal reliability alpha coefficient was .86 .

\subsubsection{Secondary Data}

The secondary data was collected from different sources, such as academic articles, journals, books, annual reports of Bangladesh Bank, labor and employment acts, and other published documents.

\section{RESULTS}

Pearson product moment correlation was used to determine the relationship between interpersonal problems and job involvement. The relationship between interpersonal problems and job involvement are shown in Table-1.

\section{Table 1}

Correlation of interpersonal problems with job involvement

Variables

The table 1 indicated that interpersonal problem is significantly negatively correlated with job involvement $[\mathrm{r}=.523, \mathrm{p}<0.05]$. Thus, the person who had high interpersonal problems had low involvement with his or her job. This result proved the hypothesis true that interpersonal problem is negatively related to job involvement. Correlation values among different types of interpersonal problems with job involvement are shown in Table 2. In table 2, the present study analyzed the eight types of interpersonal problems separately to clarify the effect of them on job involvement independently. 


\section{Table 2}

Correlation of different types of interpersonal problems with job involvement:

$$
\text { Variables }
$$

Domineering/ Controlling

Vindictive / Self-centered

Cold / Distant

Socially Inhibited

Nonassertive

Overly Accommodating

Self-Sacrificing

Intrusive/Needy
$-.106$

$-.314^{*}$

$-.522^{* *}$

$-.012$

$-.284$

$-.515^{* *}$

$-.302 *$

$-.500 * *$

Note: ${ }^{*} \mathrm{p}<.05$, two-tailed ${ }^{* *} \mathrm{p}<.01$, two-tailed

Table 2 indicates that all types of interpersonal problems are harmful for employees and results less involvement with their job. But three domains (cold / distant, overly accommodating and intrusive/needy) are significantly negative related with job involvement.

Table 3 shows the result of regression regarding interpersonal problems and job involvement. Interpersonal problems is significant negative relationship with job involvement $(\beta=-.56, \mathrm{p}<.001)$.

Table 3

Regression regarding interpersonal problems and job involvement

\begin{tabular}{|l|l|l|l|}
\hline & \multicolumn{3}{|c|}{ Job involvement } \\
\hline Predictors & $\boldsymbol{\beta}$ & $\mathbf{R}^{\mathbf{2}}$ & $\mathbf{\Delta} \mathbf{R}^{\mathbf{2}}$ \\
\hline Control Variables & & .07 & .07 \\
\hline $\begin{array}{l}\text { Interpersonal } \\
\text { problems }\end{array}$ & $-0.56^{* * *}$ & 0.38 & $0.30^{* * *}$ \\
\hline
\end{tabular}

Note: $\mathrm{N}=250$ *** Significance level $<.001,{ }^{* *}$ Significance level $<.01 *$ Significance level $<$ .05 Reliabilities $(\alpha)$

\section{Discussion}

The importance of job involvement in human resource management and organizational behavior research is proved due to its clear and significant linkages with outcomes such as job performance, job satisfaction, organizational citizenship behavior, job stress, turnover intention and organizational commitment. The objective of this study was to investigate the relationship between interpersonal problems and job involvement, to explore how interpersonal problems effect on job involvement and to examine what types of interpersonal problems in workplace create more negative impact on job involvement. The results of the study revealed that the hypothesis developed in this research study got significant support and proved that interpersonal problem is negatively correlated to job involvement. Thus the people who are suffering from interpersonal relationships are less involved with their job. The study also found that the people who are mostly face problems in cold / distant, overly accommodating and intrusive/needy domains in case of interpersonal 
relationship; they are more at risk to be less involved with job. Overall study proved the significance of interpersonal problems with job involvement. This clearly indicates that those organizations that have employees suffering from interpersonal problems are less involved with their job than those organizations who do not suffer from interpersonal problems.

\section{MANAgerial Implications and FutURE Research DiRections}

The practitioners and human resource managers can get insight from the findings of this study that interpersonal problems can decrease job involvement. It will not only decrease job involvement but indirectly or directly it will affect several other outcomes associated with job involvement. It will decrease the $\mathrm{OCB}$, creativity, employee's in-role performance and it will increase job stress, turnover intention of the employees. Human resource managers and organizational development practitioners should focus on the culture, design and environmental factors which foster the interpersonal problems of the employees. Future research should look at the different mediators and moderator involved in interpersonal problems and job factors. The study is recommended with other outcomes such as creativity, burnout, turnover intention, psychological contract breach and cynicism. A longitudinal study is recommended to test the findings of our study in different context.

\section{CONCLUSION}

The present study indicates that studies on personality traits are necessary for understanding the underline patterns of individual issues to identify the interpersonal problems. More research still required in this field to discover the relationship with lot more other factors. Some limitations like economical, time and manpower hindered this study in different ways such as - the study was conducted only in Dhaka, sample size was too small, scales for measuring were not in Bengali version etc. So the study recommends further research on larger sample from different areas of Bangladesh, that is proper representative sample and with better methodological sophistication.

\section{REFERENCES}

Alden, L. E., Wiggins, J. S., \& Pincus, A. L. (1990). Construction of circumplex scales for the Inventory of Interpersonal Problems. Journal of Personality Assessment, 55 (3\&4). 521-536.

Berscneid, E., $\mathcal{E}$ Reis, H. T. (1998). Attraction and close relationships. In D. T. Gilbert,S. T. Fiske, \& G, Lindzey (Eds.), The handbook of social psychology (4th ed.Vol. 2, pp. 193281). New York: Oxford University Press.

Blau, G. J. (1986). Job involvement and organizational commitment as interactive predictors of tardiness and absenteeism. Journal of Management, 12, 577-584.

Blau, G., \& Boal, K. (1987). Conceptualizing how job involvement and organizational commitment affect turnover and absenteeism. Academy of Management Review, 12(2), 288-300.

Blau, G., \& Boal, K. (1989). Using job involvement and organizational commitment interactively to predict turnover. Journal of Management, 15(1), 115-127.

Gould S., \& Werbel, J. (1983). Work involvement--A comparison of dual wage earner and single wage earner families. Journal of Applied Psychology, 68, 313-319. 
Gilberg, K.R. (1993, April). Open communications provide key to good employee relations. Supervision, 54 (4). [EBSCOhost). University of Phoenix Online Collection. Available: http://ehost.epnet.com: (2000, September 16).

Hackman, J.R., \& Lawler, E.E., III. (1971). Employee reactions to job characteristics. Journal of Applied Psychology. 55, 259-286.

Hackett, R. D., Bycio, P., \& Hausdorf, P. (1992). Further assessment of a three-component model of organizational commitment. Academy of Management Best Paper Proceedings. pp. 212-216.

Horowitz, L. M., Rosenberg, S. E., \& Bartholomew, K. (1993). Interpersonal problems, attachment styles, and outcome in brief dynamic psychotherapy. Journal of Consulting and Clinical Psychology, 61(4), 549-560.

Kanungo, R.N. (1979). The concepts of alienation and involvement revisited. Psychological Bulletin. 86, 119-138.

Kanungo, R.N. (1982a). Measurement of Job and Work Involvement. Journal of Applied Psychology. 67 (3), 341-49.

Kanungo, R.N. (1982b). Work alienation: An integrative approach. New York: Praeger.

Kanungo, R. N. (1982). Measurement of job and work involvement. Journal of Applied Psychology, 67 (3), 341-349.

Kahn, W.A. (1990). Psychological conditions of personal engagement and disengagement at work. Academy of Management Journal. 33, 692-724

Kiesler, D. J. (1983). The 1982 interpersonal circle: A taxonomy for complementarity in human transactions. Psychological Review, 90, 185-214.

Knoop \& Robert, (1995). Relationships among job involvement, job satisfaction, and organizational commitment for nurses. Journal of Applied Psychology, Nov 95, Vol. 129 , Issue 6.

Knotts, T. (1996, July 8). Workplace stress doesn't have to kill you. Business Journal Serving Fresno \& the Central San Joaquin Valley, 322013. [EBSCOhost]. University of Phoenix Online Collection. Available: http://ehost.epnet.com: (2000, September 16).

Lawler, E.E., III. \& Hall, D.T. (1970). Relationship of job characteristics to job involvement, satisfaction and intrinsic motivation. Journal of Applied Psychology. 54, 305-312.

Lodahl TM, Kejner M. (1965). The definition and measurement of job involvement. Journal of Applied Psychology, 49: 24-33.

Maslack, C. (1997). The truth about burnout: How organizations cause personal stress and what to do about it. San Francisco: Jossey-Bass.

Pierce, T., \& Lydon, J. (1998). Priming relational schemas: Effects of contextually activated and chronically accessible interpersonal expectations on responses to a stressful event. Journal of Personality and Social Psychology, 75, 1441-1448.

Randolfi, E. (1996, December 12-13). Stress management evaluation [online]. Available: http://imt.net/ randolfi/StressMgtEval.html: (2000, September 14).

Schultz, D.P. \& Schultz, S.E. (1994). 6th ed. Psychology and work today: An introduction to Industrial and Organizational Psychology. New York: Mc Millan. 